\title{
THE IMPACT \\ OF SOME EMERGING TECHNOLOGIES IN MODERN MILITARY ACTIONS
}

\author{
Aurelian RAȚIU \\ aurelian_ratiu@yahoo.com \\ Onisim ROȘU \\ cnmdcrosu@gmail.com \\ “NICOLAE BĂLCESCU” LAND FORCES ACADEMY, SIBIU, ROMANIA
}

\begin{abstract}
Among the emerging technologies, artificial intelligence represents nowadays an area of interest for all of the states around the world, making the technological progress a huge step in human evolution. The future role of the man in military actions will not be to fight in the field anymore, making decisions on how and when to use the weapons in order to stop the incoming enemy while also respecting the international laws. With the help of technology, humanity could provide its much needed security and put an end to conflicts regardless of their nature, because devices are not capable of emotions and subjectivism, making them transparent and objective and transforming the decision making process into a simpler, fairer and legal action. Technology represents the future and man should adapt to it as soon as possible in order to reach the best outcomes even when it comes to war.
\end{abstract}

\section{KEYWORDS:}

Emerging technologies, artificial intelligence, military operations, operational environment, robots

\section{Introductory and methodological aspects}

Technology is advancing at an impressive rate. Technological development cannot be stopped and that is why humankind in general and the military in particular must adapt to this new challenge. Mlitary organizations compete or fight, and one of their means is technology.

The operational environment is constantly changing due to new technologies that have been implemented in the construction of combat systems or have been used by opponents in civilian or dualuse facilities or equipment. Automation, computerization and robotization are conclusive evidence of the trend of technology evolution in military organizations, the goal being to obtain processes less dangerous to humans, with low collateral material damage, but more efficient in achieving goals / objectives.

Our research aims at highlighing the impact of artificial intelligence on military 
actions and the development of a device that represents a narrow/weak form of artificial intelligence and is able to recognize a color spectrum, a process that can also be useful in recognizing targets in the battlefield.

\section{The importance of using emerging technologies and artificial intelligence in modern conflict zones}

In order to fully understand why artificial intelligence could play such an important role in the modern war, we firstly need to understand the difference between the various types of war. There are plenty of definitions for the subject, but we need to address those that differentiate artificial intelligence from human intelligence. So, artificial intelligence takes place when a device becomes fully conscious about its actions, has the capability to be wise, can store information, learn, make decisions and has its own initiative. Basically, when the machine, on its own, thinks like a human being, it can be considered artificial intelligence. Alan Turing extends this model even further and says that artificial intelligence happens when we cannot differentiate the answers given by those devices from the answers given by humans. Artificial intelligence can be of two types based on its position in the evolutionary process: weak artificial intelligence and strong artificial intelligence, (Epure, 2014, p. 42). Weak artificial intelligence is today's type of artificial intelligence, characterized by the ability to perform specific tasks: voice and visual recognition, virtual support (Amazon Alexa, Apple Siri, Google Assistant), buying suggestions, sales predictions, weather forecasts or selfcontained cars (Dickson, 2017). The weak artificial intelligence is characterized as extremely fast and intelligent in the field for which it was created, but is limited to performing pre-defined sets of functions without emotion, beliefs, sensitivity or consciousness. In the next phase, we could have access to artificial intelligence of human level or strong artificial intelligence, which has the ability to understand and rationalize in its environment like a human being. It would have autonomous learning capability to connect to the architecture of the Internet and amplify its capabilities by accessing the data of the Internet of things (IoT) (IoT is a system of interrelated computing devices, mechanical and digital machines with unique identifiers that have the ability to transfer data over a network without requiring human interaction). It could achieve information gathering, learned through various algorithms, becoming thus an innovative, creative and confident system for decision-making. In time, this kind of intelligence would be able to take on every role man performs.

Imagining what this could mean for the humankind can surely make everyone feel more optimistic about war situations, because there will not be so many life losses and so much material damage involved.

Although scenarios in which machines fight the hardest parts of any war for us are impressive, the progress of artificial intelligence has of course its downsides. We need to take in consideration that sometimes emotions and subjectivism can lead to better outcomes than pure objectivism and self developed algorithms.

We talked about the definitions, the downsides and the meaning that artificial intelligence could give to wars, but now we need to look at the positive impact it could generally have on society. Machines having artificial intelligence could be used to reduce pollution (especially $\mathrm{CO} 2$ ) and to stop climate changes, because through them we can develop new alternative power sources. Another domain in which this could be used is medicine, where artificial intelligence will do the researching for cures to diseases like cancer or AIDS. If we look at the problem from this perspective, this type of intelligence can surely have an amazing impact on the world.

The realistic scenario would be that this type of intelligence remains at the 
current stage, with current capabilities given and controlled strictly by man. The overall picture offered by the future operational environment requires military with exoskeletons connected by advanced information systems that provide real-time images and visualization to leaders. The war will continue to be asymmetrical and irregular, taking place in the urban environment.

Another subject for debate is the legitimacy and morality of developing and putting these types of systems into the current combat space, of mobile and autonomous robotic systems capable of selecting and dismantling the target according to current procedures, doctrines and laws, planned and accepted at international level.

These weapons should be used in accordance with the requirements of the the international law on armed conflict and humanitarian rights. Since the device is not human and its functions are not supported and controlled by the intervention of a human being, the decisions of the system to neutralize a human target are seen as illegal and unethical. The problem of exercising justice and thus finding a guilty person is also hard in the event of system errors, which makes the legal act difficult, given that the accident was caused by an autonomous device not controlled by a human with decision-making capacity. At the same time, robotic and automatic systems cannot be fined, discouraged or punished for committing such acts; and the only defendant will be the man, but what individual and to what extent are problems that are still unresolved at present.

A meeting of the states under the United Nations Convention on conventional arms to discuss the lethality of autonomous weapons took place between 25-29 March 2019 and 20-21 August 2019 in Geneva, Switzerland. The meeting concluded with the next rules: human control over these systems can be exercised in five courts as discussed at the meeting, namely
(The Convention on Certain Conventional Weapons' Group of Governmental Experts on Emerging Technologies in the Area of Lethal Autonomous Weapons Systems, 2019):

- the man defines the target according to the law of armed conflict;

- the man does not activate the system if the weapon does not know exactly what it is intended to engage;

- the man confirms the target selected by observing the law of armed conflict;

- the man confirms the system's decision to engage the target in an efficient way;

- the man has an obligation to deactivate the system if it does not work, in accordance with the international law of armed conflict.

A single command and control center is required to achieve the unit in action and to concentrate the effort so that there is synchronization in action. The nature of future wars is intended to destabilize the entire command and control center so as to eliminate dimension connections, with the aim of causing disorientation in decisionmaking and inability to act due to a lack of information. Electronic War "includes the use of all available electronic and computer means to neutralize the electronic and communication systems of the enemy while aiming at maintaining the integrity of their systems at an operational level" (Epure, 2014, p. 338). A priority within the development of current combat capabilities is the development of ubiquitous and omniscient autonomous vehicles, focusing those devices on navigation in all areas of action, land, air, sea and implicitly spatial and subsea (National Academy of Engineering, 2018). A major advantage of artificial intelligence, present at the stage of development and integration within all areas of action, is the dominance of the ISR (intelligence, surveillance and recognition) of the geographical area, both in the military conflict space and in residential, commercial, industrial, civil areas, to create an inclusive spectrum of the global security 
situation found in all fields of activity and in all areas of the operational space (Erwin, 2018). Artificial intelligence could cover broad areas of activity, with certain anomalies, possible aggression, and selfsufficient learning to be able to restructure and adapt to reject attacks that demonstrate the physical and material integrity of a force or system.

A report by major General Mick Ryan suggests that a highly capable and resilient tactical unit in 2030 can be made up of 250 to 300 human soldiers and several thousand robotic systems of different sizes and functions (Layton, 2018). This approach could free staff that can be redistributed in areas where the art of war requires intelligence functions that entail leadership and creativity, training and education, planning, and, most importantly, command and control.

Another important aspect of the spectrum of war in the future is the supervision of the quality of soldiers on the combat space, making these more effective, together with increasing performance in meeting mission requirements as well as digitizing operations planning and facilitating recruitment and selection programs with individual military characteristics as a point of reference. On this basis, specialists could obtain a comprehensive assessment of the individual's skills, experience, personality, strengths, weaknesses or psychological condition. Autonomous learning systems could also help align human talent with mission requirements and optimize team composition for specific missions based on expertise and personality, or past unit performance under different conditions.

\section{Artificial intelligence within military systems}

Weapons systems are influenced by the development of artificial intelligence, which causes a radical change in capabilities, functions and outcomes in the accomplishment of certain actions and requirements. Whether we are talking about smart rockets capable of locating, recognizing, following and neutralizing the target quickly, accurately and without collateral damage, or whether we are talking about various robotic systems belonging to a variety of fields of activity and performing complex functions, we can conclude that the operational environment has changed with the implementation of these improvements in the fulfilment of the battlefield missions. The arms race with such systems is fierce and indispensable for strategic stability. Information domination, the integration of ISR capabilities into a macro system connects all digital devices, and thus man, through digital development, will help deter hostile action in an asymmetric war. The robots will replace the current soldier, because of the existence of LAN-type connections to facilitate teamwork, the permanent location of these devices, their spatial integration, their ability to operate in chemical, radioactive, biological environments, and thus the development of their ability to understand non-verbal communication, the culture of the areas where the armed actions take place and natural language.

One of the great advantages of implementing artificial intelligence in the combat space is the precision of action and the speed of annihilating the enemy's potential for action, which produces the socalled clean war, a war without collateral victims. The attack will be carried out by surgical strikes, with a fixed and defined target, intended to destabilize or annihilate the target (Epure, 2014, p. 314). These blows will not interfere with civil structures, and the rate of mortality and material losses of the civilian population will be substantially reduced.

Surgical strikes will have a predefined trajectory to the target for destruction or damage. In their construction, propulsion is envisaged, which will imprint a certain speed of travel; the mass, and the ballistic capacity will be calculated according to these parameters; the strikes 
succeeding in following the target without human involvement and the changing of the path will not be an impediment (Epure, 2014, p. 60).

Furthermore, in order to locate and track targets, missile systems can rely on the simplest location and coordination system provided through the interaction of multiple satellites. To improve GPS receiver accuracy, differential GPS (DGPS) has been created. Differential GPS (DGPS) works by identifying common errors and then eliminating the influence of common errors found to improve positioning accuracy (Chivers, 2017).

Regardless of the space in which the military evolves, the technology of armaments is constantly developing, and it is able to achieve an incredible performance that makes the methods of fighting and the ways of remedying armed conflicts more efficient.

Another consequence of the impact of technical progress is the provision of a large volume of data that must be processed in real time, involving the acquisition and selection of useful and necessary information performing the tasks in the battle space, as well as creating premises that will facilitate several decisions in the same time.

By means of these artificial intelligence-enhancing tools, military analysts can collect, disseminate and process data with a double or even a triple volume over the same period of time in comparison to the execution of these activities in a traditional way, thus reducing damage and spillover damage; consequently, it increases the supply of critical information to the battle space in a more efficient way and in less time.

Authorizing a robotic system to make critical battle decisions depends on political and military leaders who address the issues of legitimacy and morality of these actions. This includes: the adequacy of the technology that has this capability, in what circumstances it should be used, whom the liability is attributable to in case of mistakes, and what limitations should be placed on the autonomy of such systems.

We consider that, in the future, the robots will be implemented in the combat space to perform certain functions, especially those of humans, in situations where the integrity and lives of people are endangered. This is why a major advantage is highlighted in the deployment of such intelligent devices, namely the reduction of human losses in theaters of operations. The difference between man and robot is evidenced by the fact that man has a greater power of reflection, the ability to analyze action possibilities, whereas the robot exhibits better reflection in action-taking, being more reliable, faster, more accurate and error-free. The non-involvement of man in armed conflict results in a decrease in the loss of human lives and the human potential could be directed to other less risky areas of activities. People could also increase their quality of life and develop knowledge and processes that would bring us closer to strategic peace and stability.

\section{Color-recognition device for use in military actions}

In order to prove that new technologies and artificial intelligence can make the difference regarding modern military equipment, we built a device that can recognize colours (as it can be seen in Figure no. 1). At the same tame, we want to emphasise the fact that building such a device is not complicated and it is easy to implement in military systems. 

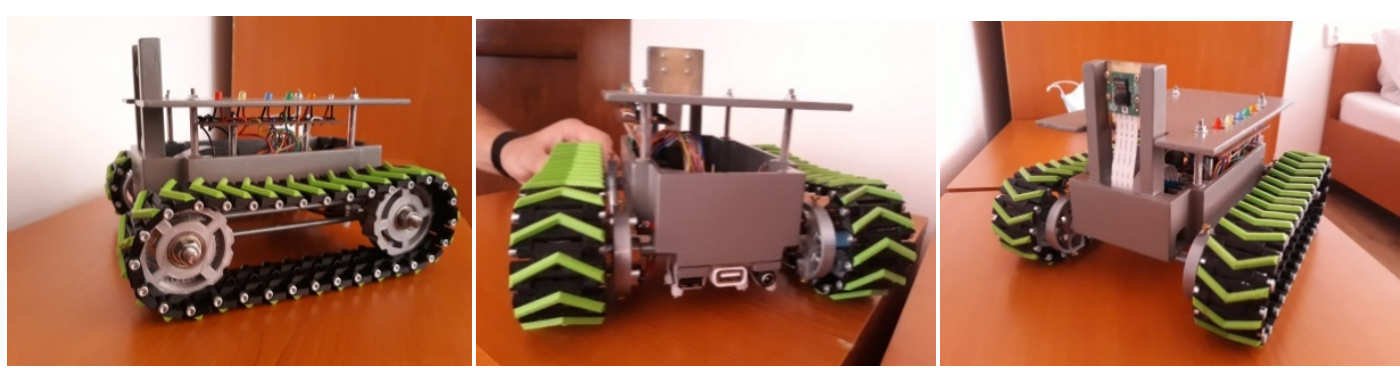

Figure no. 1: Installation viewed from several profiles

(Source: Authors)

The point of reference from which we started was the use of this device, which, with particular attention and some help can produce incredible results, starting from camouflage recognition, to recognition of enemy targets and their profile, permanently having the capacity to store the data obtained from the battlefield.

A video camera with a better resolution than that of a webcam was installed on the prototype vehicle and, through the operating program, the color of an object is recognized and the LED (Figure no. 2) corresponding to the color, mounted on a panel of the vehicle, lights up.

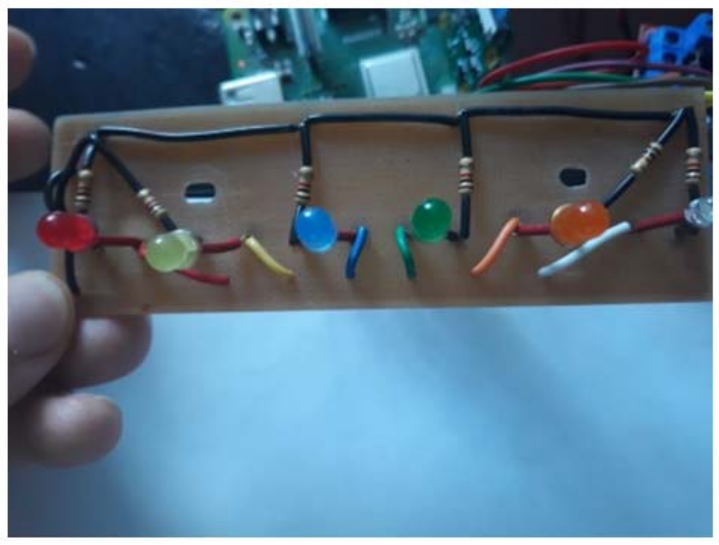

Figure no. 2: LED panel

(Source: Authors)

Even more, the storage capacity is produced by an SD card, practically the design draws simple comparative lines with a robot that has narrow artificial intelligence, and is a basic example of the functionality of these types of systems.
By setting up a steering algorithm and by installing tracks on a vehicle prototype, this can be moved remotely by an operator via computer, remote control, and other remote drives. The present design, through the installation of tracks, is also meant to demonstrate the importance of adapting the system to the combat space, taking into account the terrain configuration and taking the necessary steps to ensure that its mobility is particularly high. At the same time, the size of the system is important, because, the smaller the size, the less the probability of detection decreases, the higher the chance of surprise and the better the possibility of penetrating areas that are difficult to reach for humans (channels, narrow areas, vents, etc.), which implies greater efficiency and utility.

\section{Conclusions}

Artificial intelligence is not only used in the military field, and its implications have an impact on human everyday life, on commercial, economic, social and medical sectors. These advances are designed to make a better life for humans, to monitor health, nutrition, to treat incurable diseases at present, to prescribe treatments and to prevent certain diseases; it can lead to an extension of life expectancy and to an improvement in the quality of life.

At present, the need for military operations conducting and planning to evolve within the armament systems is achieved simultaneously with the evolution of the technology. The effectiveness of weapons 
that have state-of-the-art technologies implemented is much higher, but we must take into account the understanding of their functioning, the conditions of their use, and also the financial and material implications and the need for an information infrastructure that allows for their correct and safe use.

The built-in device attests a simplistic form of narrow artificial intelligence. It has the ability to select data, analyze it, process it and then transmit it to the operator, both in a digital as well as in a physical form, materialized by lighting the LED corresponding to the identified color.
The device, in its current form, does not complete another action alone, its purpose being to provide information to the human user; in this way, its autonomy is limited by the decision-making capacity attributed to man. This device is a miniaturization of a system / vehicle that can be found in the operating environment. Its improvement can be achieved by transmitting the information to another military system, possibly a hitting system, assuming that a possible target of the opponent has been recognized / identified.

\section{REFERENCES}

Chivers, M. (2017). Differential GPS Explained. Available at: https://www.esri.com/ news/arcuser/0103/differentiallof2.html, accessed on 09 September 2021.

Dickson, B. (2017). What is Narrow, General and Super Artificial Intelligence. Available at: https://bdtechtalks.com/2017/05/12/what-is-narrow-general-and-super-artificialintelligence/, accessed on 23 March 2020.

Epure, I. (2014). Inteligența artificială din câmpul de luptă integrat. Bucharest: Militară Publishing House.

Erwin, S. (2018). NGA official: Artificial intelligence is changing everything, "We need a different mentality". Available at: https://spacenews.com/nga-official-artificial-intelligenceis-changing-everything-we-need-a-different-mentality/, accessed on 20 March 2020.

Layton, P. (2018). Our New Model Robot Armies. Small Wars Journal, available at: https://smallwarsjournal.com/jrnl/art/our-new-model-robot-armies, accessed on 20 March 2020.

National Academy of Engineering. (2018). Autonomy on Land and Sea and in the Air and Space: Proceedings of a Forum. Washington, DC: The National Academies Press, available at: https://www.nap.edu/read/25168/chapter/2, accessed on 23 March 2020.

The Convention on Certain Conventional Weapons' Group of Governmental Experts on Emerging Technologies in the Area of Lethal Autonomous Weapons Systems. (2019). Report of the 2019 session of the Group of Governmental Experts on Emerging Technologies in the Area of Lethal Autonomous Weapons Systems. Available at: https://documents.unoda.org/wpcontent/uploads/2020/09/CCW GGE.1 20193 E.pdf, accessed on 04 September 2021. 